\title{
Author Correction: Single cell transcriptome profiling of retinal ganglion cells identifies cellular subtypes
}

\author{
Bruce A. Rheaume ${ }^{1}$, Amyeo Jereen ${ }^{1}$, Mohan Bolisetty², Muhammad S. Sajid ${ }^{1}$, Yue Yang ${ }^{1}$, Kathleen Renna , \\ Lili Sun ${ }^{2}$, Paul Robson (10) ${ }^{2,3}$ \& Ephraim F. Trakhtenberg (1) ${ }^{1}$
}

Correction to: Nature Communications; https://doi.org/10.1038/s41467-018-05134-3; published online 17 July 2018

The original version of the Supplementary Information file associated with this Article contained an error in Supplementary Fig. 2. In panel $c$, the graph was inadvertently replaced with a duplicate of the graph in panel a. The error has now been fixed and the corrected version Supplementary Information PDF is available to download from the HTML version of the Article.

Published online: 07 August 2018

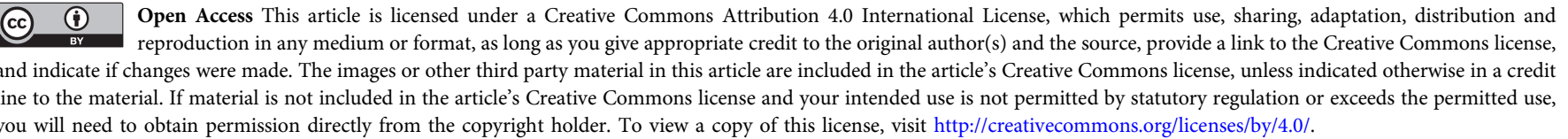
you will need to obtain permission directly from the copyright holder. To view a copy of this license, visit http://creativecommons.org/licenses/by/4.0/.

(c) The Author(s) 2018

\footnotetext{
${ }^{1}$ Department of Neuroscience, University of Connecticut School of Medicine, 263 Farmington Ave, Farmington, CT 06030, USA. ${ }^{2}$ The Jackson Laboratory for Genomic Medicine, Farmington, CT 06032, USA. ${ }^{3}$ Institute for Systems Genomics and Department of Genetics \& Genome Sciences, University of Connecticut School of Medicine, Farmington, CT 06032, USA. Correspondence and requests for materials should be addressed to

E.F.T. (email: trakhtenberg@uchc.edu)
} 